\title{
Molecular Genetics of Inherited Antithrombin III Deficiencies
}

\author{
Edwaro V. Prochownik, M.D., Ph.D. Ann Arbor, Michigan
}

The cloning of antithrombin III (ATIII) complementary deoxyribonucleic acids and the determination of the ATIII gene structure have permitted a systematic evaluation of the molecular basis for inherited ATIII deficiencies. Sixteen kindreds with the most common form of the deficiency, in which plasma ATIII antigen levels and activity are proportionately reduced, were studied. Two polymorphic deoxyribonucleic acid markers were used to resolve parental ATIII alleles and to trace their inheritance patterns. In 15 of 16 cases, the structure of the affected ATIII allele was indistinguishable from normal, suggesting that relatively small mutations, resulting in gene inactivation, are responsible for the lower ATIII levels in these affected families. In the remaining kindred, complete deletion of one ATIII allele was seen. Also investigated was the molecular basis for a qualitative form of ATIII deficiency in a French-Canadian family with normal levels of immunoreactive protein but only half the expected levels of serine protease inhibitor activity. Using polymorphic markers, the abnormal allele was identified, cloned, and partially sequenced from the propositus. A single $\mathbf{G} \rightarrow \mathrm{A}$ transition was seen in the first base of codon 382 , resulting in an alanine $\rightarrow$ threonine substitution in the defective protein. This mutation, together with others in this vicinity, defines a minimal length for a fully functional thrombin-binding domain.
From the Section of Hematology/Oncology, Department of Pediatrics, and the Committee on Cellular and Molecular Biology. University of Michigan School of Medicine, Ann Arbor, Michigan. Requests for reprints should be addressed to Dr. Edward V Prochownik, Department of Pediatrics, University of Michigan Medical Center, M7510 MSRB 1, Box 0684, Ann Arbor, Michigan 48109-0684. ntithrombin III (ATIII) deficiency can be clivided A into two general categories, acquired and inherited. The former results from a decrease in the synthesis of ATIII such as occurs in advanced hepatic disease. It may also result from an increased loss of ATIII as seen in the protein-losing enteropathies and nephropathies. Inherited ATIII deficiency, on the other hand, has a familial basis and demonstrates a classic mendelian mode of autosomal-dominant inheritance [1-3]. Its incidence has been estimated at as low as $1: 2,000$ to $1: 5,000$ in the general population, although more recent studies have indicated it to be somewhat less common [4]. Nevertheless, it probably represents one of the more prevalent forms of congenital coagulopathies.

Inherited ATIII deficiency has classically been divided into two basic types: type I, in which both antigenic levels and functional activity of ATIII are proportionately reduced, and type II, in which normal or near-normal antigen levels are found in association with dysfunctional ATIII activity [2]. The former type probably accounts for 80 to 90 percent of inherited deficiencies and is associated with a remarkably homogeneous 50 to 70 percent reduction in plasma ATIII levels in the affected persons. Type II deficiencies were originally discovered after observing abnormal progressive ATIII or heparin cofactor activities despite what appeared to be normal plasma ATIII antigen levels $[5,6]$. We now appreciate that the type I deficiencies probably result from genetic mutations that produce silent ATIII alleles, whereas type II deficiencies result from point mutations in the ATIII protein that cause abnormal thrombin or heparin binding.

\section{NORMAL AND ABNORMAL ATIII GENES}

The cloning and characterization of the ATIII gene and its complementary deoxyribonucleic acids (cDNA) have now made possible a detailed analysis and a more comprehensive understanding of the molecular basis of ATIII deficiencies [7-10]. Of central importance to this process has been the identification of restriction fragment length polymorphisms (RFLPs) that have allowed for the separation of parental alleles and for the ability to establish which of two alleles in affected persons is the mutated one. Two such RFLPs have been identified. One results from a silent nucleoticle change in exon IV of the coding region of the gene that either preserves or destroys a PstI restriction enzyme site [11]. The second results from an insertion/deletion in the $5^{\prime}$-flanking region [12] (Figure 1). When genomic DNA is digested with the restriction enzyme PstI and subjected to Southern blotting using a fulllength cDNA probe, these different alleles can be resolved $[11,13]$. They have been referred to as $(+)$ or $(-)$ to connote the presence or absence of the PstI site in exon IV and as fast or slow to indicate the size clifferences in the 5 '-flanking region PstI fragments. 


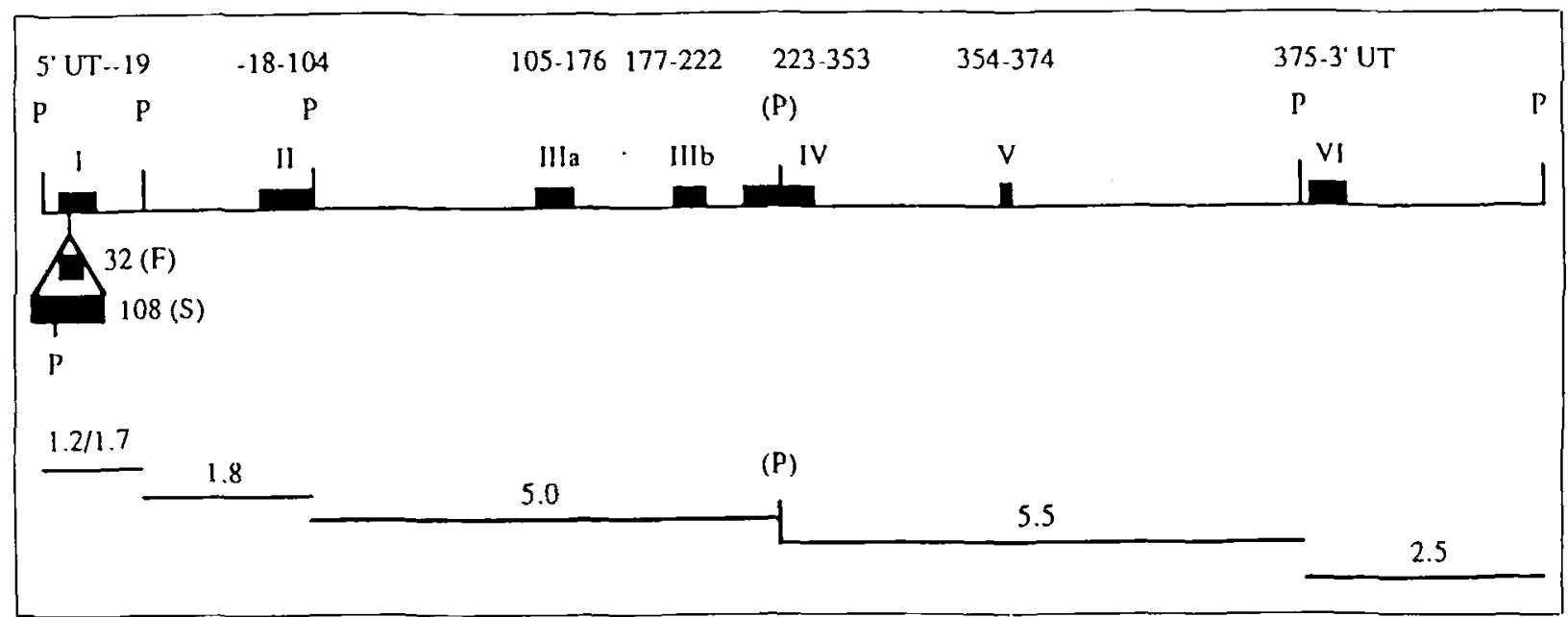

Figure 1. Map of the human ATIII gene. The gene is composed of seven exons (boxes, numbered I to VI) and six introns distributed over approximately $16 \mathrm{~kb}$ of DNA Numbers above exons indicate the amino acids encoded by that exon. Numbers -18 and -19 refer to signal peptide amino acids. Pstl restriction sites are indicated with the polymorphic Pstl site in exon IV indicated as P. The fragments generated by Pstl digestion are shown below the map. The $1.8-\mathrm{kb}$ and $2.5 \mathrm{~kb}$ fragments are invariant in size. The presence of the polymorphic Pstl site will result in the generation of two fragments of 5.0 and $5.5 \mathrm{~kb}$, whereas its absence will generate a $10.5-\mathrm{kb}$ fragment. Exon I may contain either a 32.base pair (bo) or 108.bp insertion in the 5'-flanking region of the gene. The latter contains a Pstl site, and therefore exon I coding sequences reside on a 1.2-kb Pstl fragment. The allele containing the 32-bp insert contains no Pstl site. Coding sequences therefore reside on a 1.7-kb Pstl fragment. Enzymes whose recognition sites flank these two insertions will generate coding fragments differing by $76 \mathrm{bp} .(\mathrm{F})=\mathrm{fast} ;(\mathrm{S})=$ slow.

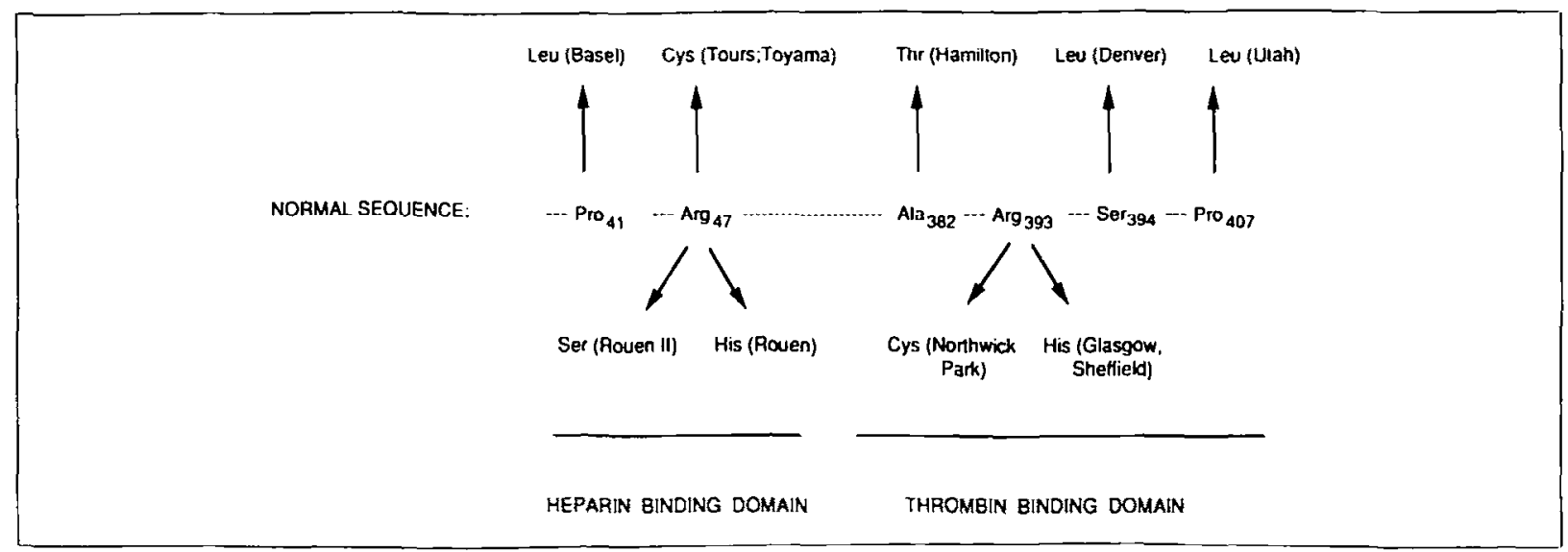

Figure 2 Mutations affecting ATIII activities. The normal sequence around the heparin-and thrombin-binding domains is shown on the middle line. The amino acids of the mutant proteins are indicated either above or below the normal sequence. Leu = leucine; Cys = cysteine; Thr = threonine; Pro = proline; Arg = arginine; Ala = alanine; $\operatorname{Ser}=$ serine; His $=$ histidine.

The presence of these two frequent polymorphisms in the ATIII gene has permitted identification of the mutant alleles in nearly all affected kindreds. For example, in a recent collaborative study, we have been successful in this regard in 15 or 16 cases [13]. Our results can be summarized as follows: (1) all affected persons appear by Southern blot analysis to have two normal-appearing ATIII genes, so the mutations that cripple the affected allele do not involve large DNA rearrangements, insertions, or deletions; (2) in one case, a total deletion of one ATIII gene was observed, thus accounting for an apparently rare form of the deficiency state.

It should be emphasized that the identification of these two polymorphisms, along with family studies, provides an unequivocal means of determining which of two normal-appearing ATIII alleles is dysfunc- tional. This has allowed the unambiguous cloning of the correct allele from genomic libraries in order to explore the basis for some of the type II deficiencies described below.

In the simplest case, the ATIII molecule can be viewed as being composed of two functional domains, one encoding heparin binding and centered around the $\mathrm{Arg}_{47}$ residue, and the other encoding the serine protease inhibitor (thrombin-binding) domain centered around $\mathrm{Arg}_{33:}$-Ser 3994 . A combination of classic protein sequencing and contemporary molecule genetic techniques has been employed to examine the basis for several of the known type II ATIII deficiencies. In all cases so far examined, single amino acid substitutions account for the observed effects on heparin or thrombin binding. Figure 2 summarizes the mutants that have so far been characterized. 


\section{A MOLECULAR CLASSIFICATION OF ATIII DEFICIENCIES}

Careful correlations between ATIII antigen levels, functional activities, and specific mutations in the ATIII protein have now demonstrated that the classic division of inherited ATIII deficiencies into only two types is probably oversimplified. For example, Bock et al [14] have sequenced the entire ATIII Utah coding region and have shown that the only mutation is one that alters the normal Pro ${ }_{407}$ to Leu [14]. Yet, persons with this mutation have consistently low ATIII levels [15]. This is clearly not a classic type II deficiency in which antigen levels are unaffected. Rather, either the single nucleotide substitution reduces the rate of messenger ribonucleic acid transcription or translation, or the mutant protein has a reluced plasma half-life. We have proposed a more refined classification scheme that takes into account these differences and that can be correlated with specific ATIII mutations (Table I) [16]. We suggest that type I deficiencies arise as a result of what is probably a heterogeneous group of disorders not unlike those causing the beta-thalassemias. These would include frame shift and nonsense mutations as well as those affecting splice junctions, promoters, and enhancers in and around the actual structural gene. In rare cases, larger deletions or rearrangements might account for the loss of gene function. Unlinked mutations might affect genes whose products are concerned with maintaining normal ATIII messenger ribonucleic acid or protein levels, although such mutations have not been described.

Type II deficiencies are of a qualitative nature in which ATIII levels and heparin binding are within the normal range but thrombin binding is defective. ATIIIs Denver and Hamilton are examples $[17,18]$. Other variants of this type include ATIIIs Northwick Park, Trenton, and Milano (Figure 2) [19].

Type IIIA deficiencies alter the heparin-binding domain and result in diminished cofactor activity while leaving progressive ATIII activity unaffected. ATIIIs Toyama, Tours, and Rouen I and II are within this group [20-23].

Type IIIB deficiencies also affect the heparin-binding domain but actually result in increased heparin binding. This has been described for ATIII Chicago, although the exact molecular defect has not been elucidated.

Type IV deficiencies are exemplified by ATIII Utah, where a single mutation accounts for a reduction in antigen level as well as for reduced thrombinbinding capacity [14].

Class V deficiencies are similar in nature to type IVs in that quantitative and qualitative defects exist simultaneously. However, in this class, heparin-binding activity is reduced, whereas thrombin binding is normal. ATIIIs Basel and Roma are cases in point $[24,25]$, although in the latter case, the exact molecular defect has not been determined.

\section{CONCLUSIONS AND PROSPECTS FOR THE FUTURE}

Clearly, the past five years have seen remarkable progress in our understanding of inherited ATIII deficiency. Particularly useful has been the cataloging of the individual point mutations that contribute to the various qualitative disorders illustrated in Figure 2,

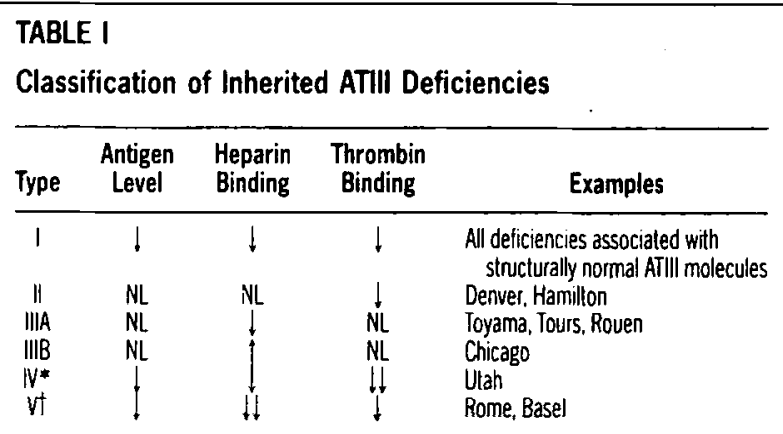

$l=$ decreased; $\uparrow=$ increased; $\mathrm{NL}=$ normal levels.

- In class IV mutations, antigen levels and heparin binding are reduced proportionally. Thrombin binding is reduced even more, owing to an alteration of the binding site. This leature distinguishes this class from the type I mutations in which antigen levels, heparin binding, and thrombin binding are all reduced proportionally.

tin class V mutations, antigen levels and thrombin binding are reduced proportionately. Heparin binding is reduced even further, presumably because of a point mutation in or near the N-terminal heparin-binding domain.

as they now allow us to estimate the minimal functional sizes of the heparin- and thrombin-binding domains. It can be predicted that new techniques such as the polymerase chain reaction [26] and direct genomic sequencing will enable workers to quickly and easily compile many additional naturally occurring mutants without resorting to long and laborious protein sequencing or molecular cloning techniques. High-efficiency oligonucleotide-directed mutagenesis [27] coupled with in vitro and/or in vivo expression [28] will permit the generation of multiple individual point mutations and determination as to how they affect various aspects of ATIII structure and function. On the clinical front, it might be expected that similar approaches will allow the production of recombinant ATIII molecules with extended in vivo half-lives that might serve as a form of second-generation replacement therapy in persons at high risk for the complications associated with inherited ATIII deficiency.

\section{REFERENCES}

1. Thaler $E$, Lechner $K$ : Antithrombin IIf deficiency and thromboembolism. Clin Haematol 1981; 10: $369-390$.

2. Nagy 1. Lasoncry $\mathrm{H}$ : Three types of hereditary antithrombin ill deficiency (abstr). Thromb Haemost 1979; 44: 187a.

3. Prochownik EV: The treatment of antithrombin III deficiency. In: Brain MD, Carbone PC, eds. Current therapy in hematology/oncology. Toronto: BC DEcker, 1985; 122-125.

4. Rosenberg RD: Action and interaction of antithrombin and heparin. N Engl J Med 1975; 292: $146-151$.

5. Sas G, Blasko G. Banhegyı D. Jako J, Palos LA: Abnormal antithrombin Ill (antithrombin III "Budapest") as a cause of familial thrombophilia. Thromb Didth Haemorrh 1974; 32 : 105-115.

6. Sas G, Peto I, Banhegyi D, Blasko G, Domjan G: Heterogeneity of the "classical" antithrombin III deficiency. Thromb Haemost 1980; 43: 133-136.

7. Bock SC. Wion KL, Vehar GA, Lawn RM: Cloning and expression of the CDNA tor human antithrombin III. Nucleic Acids Res 1982; 10: 8113-8125.

8. Prochownik EV, Markham AF, Orkin SH: Isolation of a CDNA clone for human antithrom. bin III. I Biol Chem 1983; 258: 8389-8394.

9. Chandra T, Stackhouse R, Kidd VJ, Woo SLC: Isolation and sequence characterization of a DNA clone of human antithrombin III. Proc Natl Acad Sci USA 1983; 80: 1845-1848. 10. Prochownik EV, Bock SC, Orkin SH: Intron structure of the human antithrombin III gene differs from that of other members of the serine protese inhibitor superfamily. J Biol Chem 1985; 260: 9608-9612.

11. Prochownik EV, Antonarakis S, Bauer KA, Rosenberg RD, Fearon E. Orkin SH: Molecu lar heterogeneity of inherited antithrombin III deficiency. N Engl J Med 1983; 308: 1549 1552.

12. Bock SC, Levitan DJ: Characterization of an unusual DNA length polymorphism $5^{\prime}-$ to the human antithrombin III gene. Nucleic Acids Res 1983; 11: 8569-8582.

13. Bock SC. Prochownik EV: Molecular genetic survey of sixteen kindreds with hereditary antithrombin III deficiency. Blood 1987; 70: 1273-1278.

14. Bock SC. Marrinan JA, Radziejewska E: Antithrombin III Utah: proline-407 to leucine mutation in a highly conserved region near the inhibitor reactive site (abstr). Am J Hum Genet 1985; 37: 145a 
15. 8ock SC. Harris JF. Schwartz CE. et al: Hereditary thrombosis in a Utah kindred is caused by a dysfunctional antithrombin III gene. Am J Hum Genet 1985: 37: 32-41.

16. Prochownik EV: The genetics of antithrombin III deficiency. In: Sas G, ed. The biology of antithrombins. Boca Raton. Florida: CRC Press (in press)

17. Sambrano JE, Jacobson LJ, Reeve EB, Manco.Johnson MJ, Hathaway WE: Abnormal antithrombin III with defective serine protease binding (antithrombin Ill "Denver"). J Clin Invest 1986: 7 : $887-893$.

18. Devraj-Kizuk R. Prochownik EV, Carter CJ, Chui OHK, Blajchman MA: Antithrombin III Hamilton: a gene with a point mutation (guanine to adenine) in codon 382 causing impaired serine protease reactivity. Blood 1988; 72: 1518-1523.

19. Erdjument H. Lane DA. Panico M. DiMano V. Morris HR: Single amino acid substitu. trons in the reactive site of antithrombin leading to thrombosis: congenital substitution arginine 393 to cysteine in antithrombin Northwick Park and to histidine in antithrombin Glasgow. J Biol Chem 1988; 263: 5589-5593.

20. Koide T, Odanı S, Takahashi K. Ono T. Sakuragawa N: Antithrombin Ili Toyama: replacement of arginine 47 by cysteine in hereditary abnormal antithrombin 1 tI that lacks heparin binding ability. Proc Natl Acad Sci USA 1984; 81: 289-293.

21. Duchange N. Chasse JF, Cohen GN. Zakir M: Antithrombin ill Tours gene: identification of a point mutation leading to an arginine to cysteine replacement in a silent deficiency.
Nucleic Acids Res 1986; 14: 2408-2412.

22. Owen MC, Borg JY, Soria J, Caen J. Carrell RW: Heparin binding defect in a new antithrombin III variant: Rouen, 47 Arg to His. Blood 1987; 69: 1275-1279.

23. Borg JY, Owen MC, Soria C, Soria J, Caen J, Carrell RW: Proposed heparin binding site in antithrombin based on arginine 47. A new vanant Rouen II. 47 Arg to Ser. J Clin Invest (in press).

24. Chang J.Y, Tran TH: Antithrombin III Basel: identification of a Pro-Leu substitution in a hereditary abnormal antithrombin with impaired heparin colactor activity. J Biol Chem 1986; 261: 1174-1176.

25. Leone G, Cotumaccio R. DeStelano V, Zanetti L: Antithrombin III Roma: a tamilial quantitative-qualitative ATIII deficiency identifiable by crossed immunoelectro-focusing and by crossed immunoelectrophoresıs. Haematologica 1983; 68: 765- 774 .

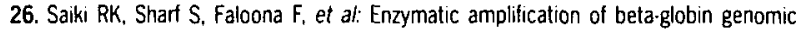
sequences and restriction site analysis for diagnosis of sickle cell anemia. Science 1985: 230: $1350-1354$.

27. Kunkel TA: Rapid and efficient site-specific mutagenesis without phenotypic selection. Proc Natl Acad Sci USA 1985; 82: 488-492.

28. Stephens AW. Siddigui A. Hirs CHW: Expression of functionally active human antithrombin Ill. Proc Nall Acad Sci USA 1987: 84: 3886-3890. 